\title{
The Guide: An Emerging Role in Participatory Theatre
}

\section{KNOWING THE RULES}

In accordance with the cultural push towards self-importance, theatre has evolved to answer an increasingly prevalent question: what if the story could be about me? The world of participatory theatre proposes an answer by casting audience members as players in the

performance. While exciting, this experience is often a frightening one; as we shed the familiar skin of passivity in favour of agency, we are forced to question the expectations placed on us in this new role What am I supposed to do? How can I be a "good" participant? What if I do something wrong? The risk of embarrassment or failure often generates apprehension in would-be players. The comfort of traditional proscenium arch theatre is that, of course, we already know how to act. We know when to applaud, when to be silent, and most importantly, we stay in our seats. Alexander García Düttmann (2011) remarks that "it belongs to the rules of the game of art" that one does not interfere with the stage proceedings. The jarring aspec of participation is that it throws that rulebook out. However, we are not doomed to remain lost at sea as we navigate the murky waters of participating. I propose a title for a new role in theatre that accompanies us on our journey, gently pushes us onto a safe pathway and critically, tells us the new rules. Enter, the guide.

\section{FORMS OF GUIDE}

\section{Performative}

Performative guides are actors wh can respond and engage with the audience while aiding them in the experience. This is the primary

focus of the research.

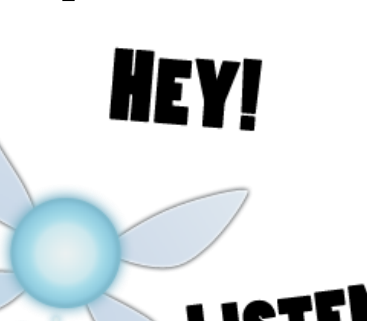

Virtual Reality

Guides are a staple of video games.

NPC avatars like Navi from the

Legend of Zelda accompany players and offer hints. VR and AR theatre uses similar digital guides.

Role-Playing

Table top role playing games like

D\&D and live-action role play

(LARP) use a game master to guide the experience.

Audio

Voice recordings

can guide the

listener through

city streets and

installations. Scar

the QR Code for an example

\section{Risk of Participation:}

- Embarrassment with athletic ability and understanding of basketball The Guide as Coach:

- A team leader who builds a supportive relationship with the players A team leader who builds a supportive re Teaches the audience basic basketball skills Provides advice while players compete On the players' side, mentoring and cheering Result:

Aided in overcoming insecurity, the players are able to focus on the value of teamwork
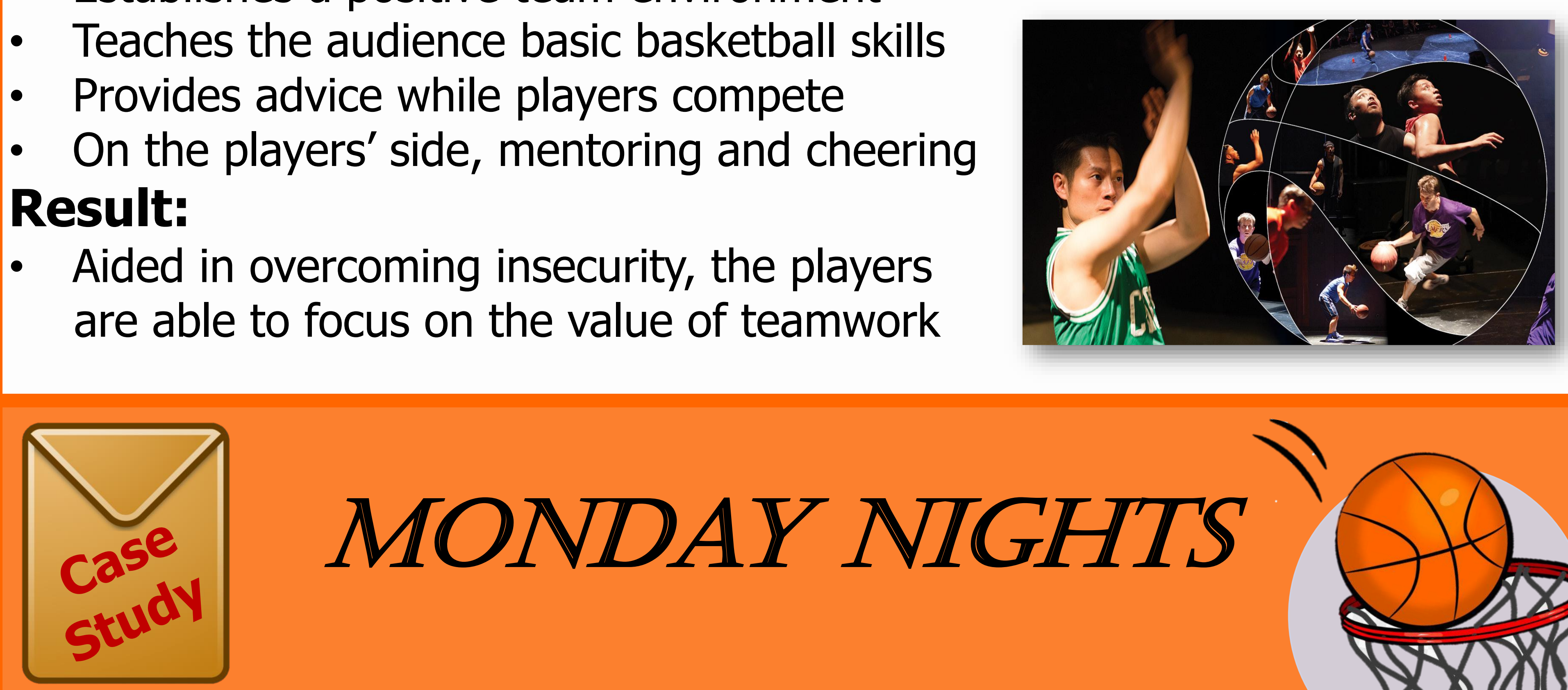

\section{MONDAY NIGHTS}

\section{Risk of Participation:}

- Fear of not knowing the proper way to participate or contribute to art The Guide as Director:

- Artists seeking to employ audience members through participation Establishes a familiar labour-for-profit exchange which

compensates the audience for completing tasks

Encourages creativity and self-advocation

Helps players do work, but also interested in communicating an ethical critique of the work Collecting Case Studies Finding relevant examples of audience participation required becoming an active player in live performances. This typically involved surveying and attending theatre festivals, and evaluating the treatment of participation.

Reading Theatre Theory Studying participatory theatre theory and applying research to case studies developed patterns. Gareth White's theory of the invitation was a significant influence on thinking about the guide as a method of inviting audience members to participate. Additionally, the Nordic LARP community's style of theatrically immersive roleplay and meta-gaming contributed to viewing participants as players. Other critical literature including game theory and Bourriaud's relational aesthetics can be found in the reference list.
Result:

The players feel safety in a familiar contract, and comprehend the commentary on the ethical issues of participatory labour

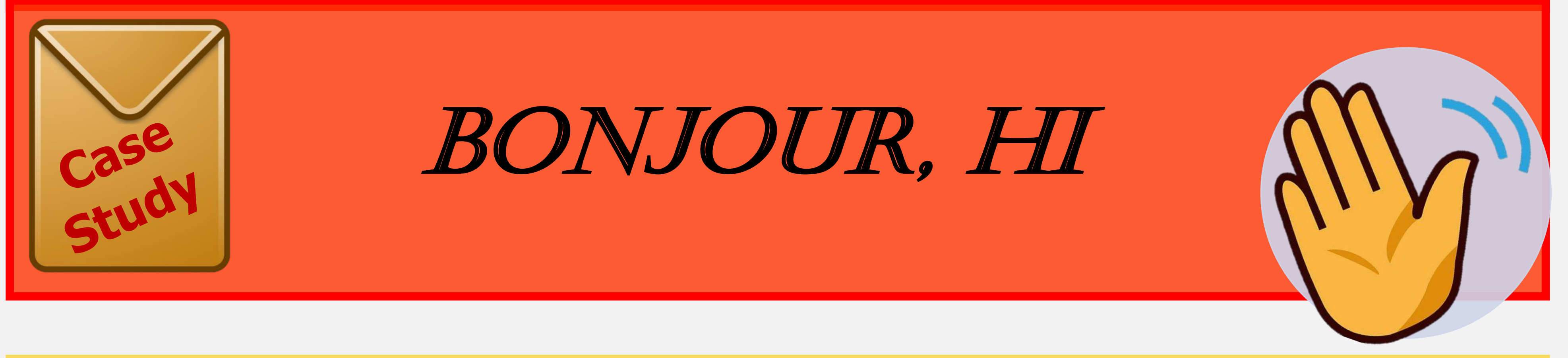

\section{Risk of Participation:}

- Frustration with puzzle-solving and inability to meet the game's challenge The Guide as Employee:

- Works for a video-store that hides puzzles among shelves of movies

- Provides insight and hints without directly solving anything

Encourages critical thinking and positive reinforcement during challenges Firmly interested in helping players succeed, though willing to allow failure which is often an important aspect of the show

Result:

Players meet the appropriate challenge level, mediating frustration and allowing an understanding of the unfolding narrative
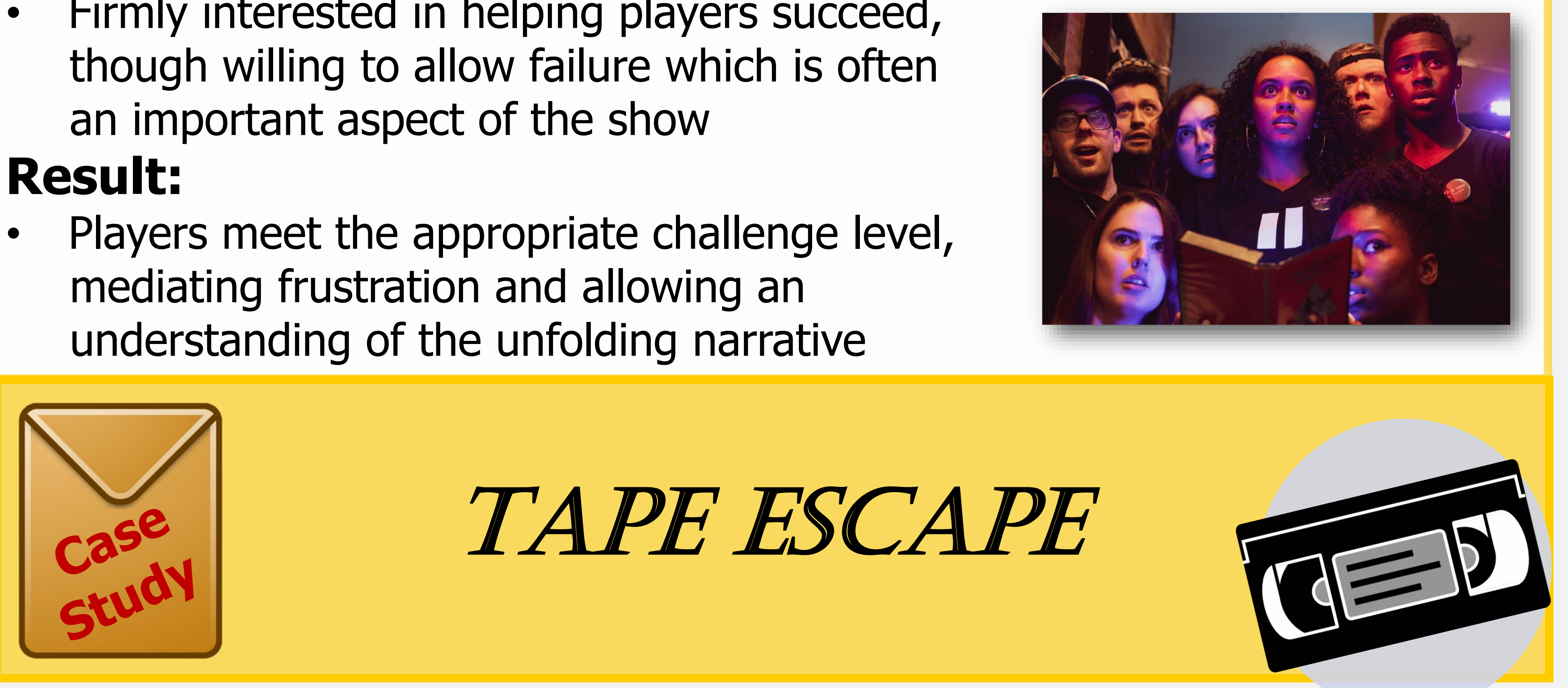

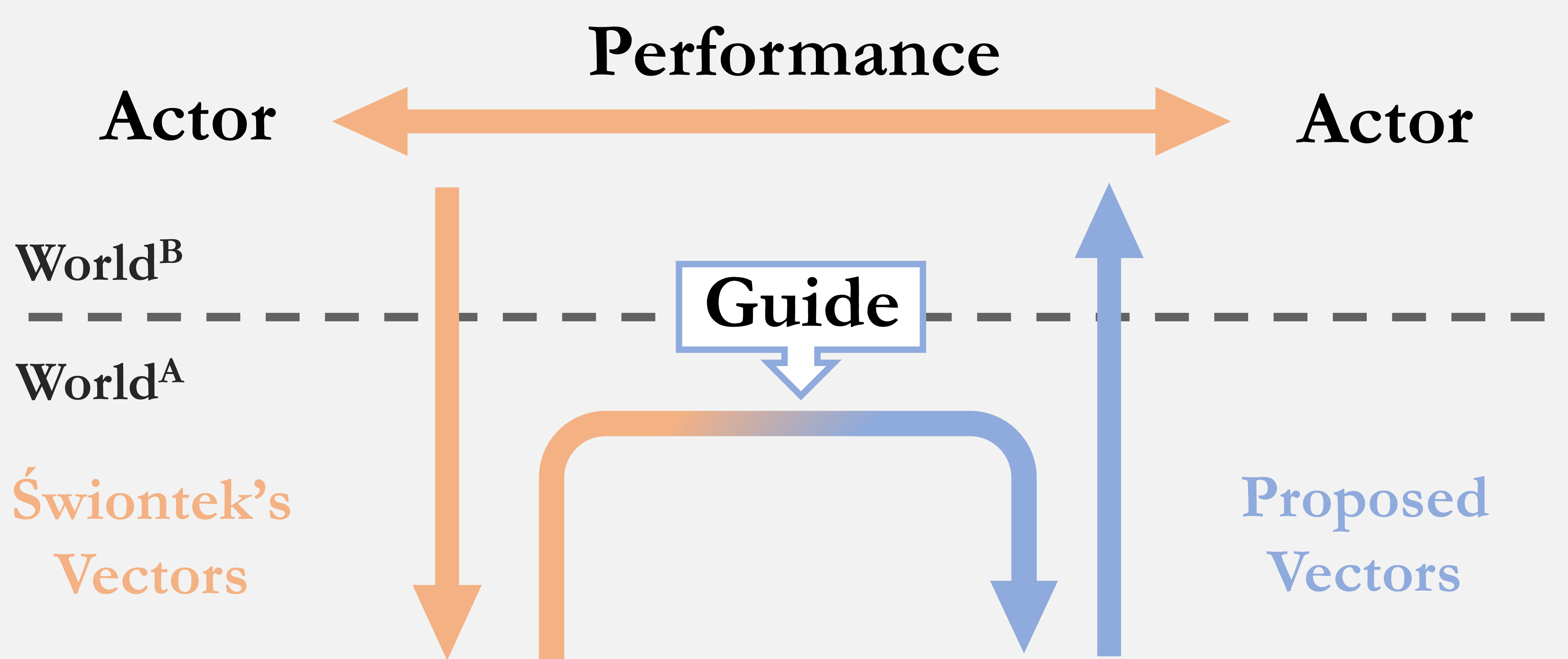

Audience

Player $\longrightarrow$ Player

UNIFYING THEORY OF THE GUIDE

Though there are significant differences in the case studies, the greatest unity lies in the directions of communication, which can be better understood through the lens of theatre theorist Sławomir Świontek (2006). He proposed we view theatre through vectors of performance carrying information and communication; Fig. 1 demonstrates how participation modifies the vectors by allowing players to send information back, establishing a communication loop between actors and participants. However, asking an audience to do this breaks the rules of theatre as we know it, requiring what Gareth White (2013) outlines as a clear and aesthetically satisfying invitation to participate. The guide, hovering on the line between the worlds of the audience and the performance, possesses the capacity to aid the audience in understanding how they can contribute without the risk of failure. Therefore, the role of the guide is to invite and facilitate communication from players by minimizing risk, allowing spectators to become active figures in the performance.

\section{CONCLUSION}

I Hate Audience Participation" - The Average Theatregoe There's no doubt that a significant portion of theatregoers feel uncomfortable participating. And why wouldn't they? Participants often face pressure to perform and anxiety at being pulled from the safety of spectatorship. I propose that the guide has the ability to help audiences overcome the risk of participation by delivering confidence, safety and comfort. Without the guide, many players would remain lost on the participatory journey and more still would be so focused on finding their way that they would fail to understand the artists' dramaturgical argument. As an adaptive role that shifts in appearance and design with each show, the guide is able to steer lost players in the right direction while easing discomfort and insecurity. Within this provided safe space, players are able to actually grapple with the purpose of their participation and the fundamental argument of the show. Therefore, it is my hope that as participatory theatre continues to grow, the guide will prevent the average theatregoer from dreading participation by facilitating meaningful play that is equal parts entertaining and aesthetically satisfying.
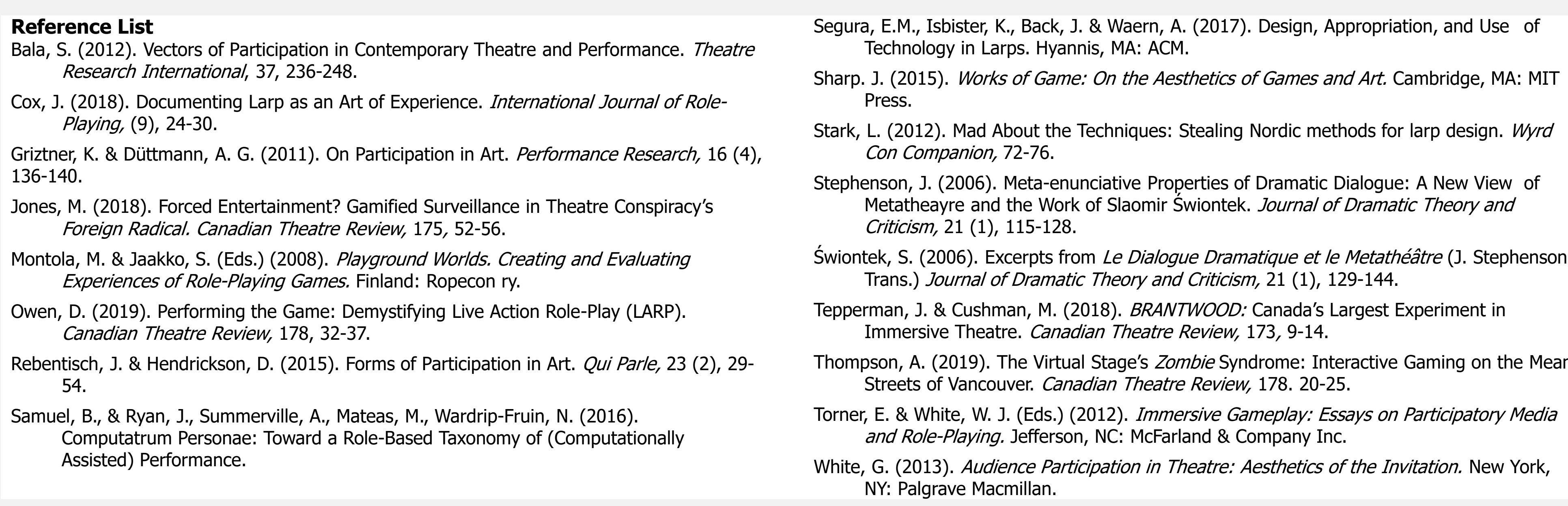